\title{
Movimientos juveniles en Brasil y México, coordenadas para un análisis de subjetivación y desmovilización social ${ }^{1}$
}

\author{
Héctor R. Andrade López²
}

Fecha de recepción: 2 de enero de 2019

Fecha de aceptación: 6 de mayo de 2019

Fecha de publicación: 30 de julio de 2019

\begin{abstract}
Resumen
Este trabajo plantea como objetivo visibilizar algunas de las repercusiones que han tenido los movimientos de \#YoSoy132, Passe Livre, \#TodosSomosPolitecnico, Ayotzinapa y algunos otros. Para ello se ha profundizado en las formas de participación y las experiencias políticas de sus jóvenes participantes, al igual que en su interrelación con su respectivo Estado y algunos de sus principales medios de comunicación. Este texto pone énfasis en algunas de las acciones de desmovilización social emprendidas por estos últimos actores, como la represión, vigilancia y mediación de las violencias estructurales y simbólicas, brindando así un propuesta de análisis que detalla la conflictualidad generada con las movilizaciones juveniles.
\end{abstract}

Palabras clave: Ayotzinapa, desmovilización social, criminalización, Passe Livre, \#YoSoy132

\section{Youth movements in Brazil and Mexico, coordinates for an analysis of subjectivation and social demobilization}

Abstract
This work aims to make shed light on the repercussions of the \#YoSoy132,
Passe Livre, \#TodosSomosPolitecnico, Ayotzinapa and other movements. To

1 Este trabajo se desprende de la tesis de Maestría, "Prácticas políticas juveniles contemporáneas. Los casos de \#YoSoy132 y \#TodosSomosPolitecnico en Ciudad de México y Movimiento Passe Livre y de los Secundaristas en Ciudad de São PauloBrasil", financiada por la UNAM. Diversos elementos que no pudieron ser abordados durante la pesquisa fueron profundizados posteriormente y son propuestos en este artículo, dando continuidad a la discusión de algunos de los movimientos juveniles de los últimos años en América Latina.

2 Maestro en Estudios Latinoamericanos, Universidad Nacional Autónoma de México (UNAM). México D.F., México. Contacto: hecf4_4@hotmail.com 
this end, the present is an in-depth study of the participation and political experiences of its youth participants, as well as their interrelations with the respective State and its key communication media. This text emphasizes some of the social demobilization actions undertaken by these actors, such as repression, surveillance and the mediation of structural and symbolic violence; thus offering a proposal for analysis that details the conflictivity generated with youth movements.

Keywords: Ayotzinapa, criminalization, Passe Livre, social demobilization, \#YoSoy132

\section{Movimentos juvenis no Brasil e no México, coordenadas para uma análise de subjetivação e desmobilização social}

\section{Resumo}

Este trabalho propõe como objetivo fazer visíveis algumas das repercussões que têm tido os movimentos de \#EuSou132, Passe Livre, \#TodosSomosPolitécnico, Ayotzinapa e alguns outros. Para aquilo se aprofunda nas formas de participação e experiências políticas de seus jovens participantes, assim como na sua interrelação com seu respectivo Estado e alguns de seus principais meios de comunicação. Este texto põe ênfase em algumas das ações de desmobilização social empreendidas por estes últimos atores, como a repressão, vigilância e mediação das violências estruturais e simbólicas, oferecendo assim uma proposta de análise que detalha a conflitividade gerada com as mobilizações juvenis.

Palavras-chave: Ayotzinapa, desmobilização social, criminalização, Passe Livre, \#EuSou132

\section{Introducción}

La reciente emergencia de los diversos movimientos y movilizaciones generadas por el impulso de miles jóvenes, tanto en México como en el mundo, ha generado una serie de apreciaciones que posan en la superficie del pesimismo y la irrelevancia. Poner sobre la mesa los temas emergentes de movimientos como \#YoSoy132, Passe Livre, \#TodosSomosPolitecnico, Ayotzinapa y otras manifestaciones, resulta un acto de desafío ante un umbral mediático y sistemático que no ve en ellos motivos por los cuales deberían de adquirir gran importancia.

Este trabajo plantea como objetivo visibilizar algunas de las repercusiones que han tenido los movimientos de \#YoSoy132, 
Passe Livre, \#TodosSomosPolitecnico, Ayotzinapa y algunos otros. Para ello es menester sumergirse en las formas en que estos jóvenes participantes se involucran en coyunturas sociales y realizan sus experiencias políticas, al igual que profundizar en dos actores de interrelación de estas experiencias: el Estado y los medios de comunicación.

De acuerdo con algunas de las interpretaciones más dominantes en el estudio de los movimientos sociales, como las expuestas por David Easton (1969), Samuel Huntington (1972) o Sidney Tarrow (2004), la victoria de un movimiento social se mide a través de los cambios generados dentro de las estructuras del sistema político. Es decir que sus demandas abanderadas tendrán que verse concretizadas en una especie de producto fabril procesado en las maquinarias institucionales. La espontaneidad de una ley, el desglose de políticas públicas en la materia o, en el mejor de los casos, la emergencia de una nueva institución pública del carácter exigido, garantizan para estos teóricos el triunfo de un movimiento social.

No obstante, cuando pensamos en estos términos a un movimiento de amplias complejidades como \#YoSoy132, podemos apreciar que éste no produjo por sí mismo una ley o reforma real en favor de la democratización de los medios de comunicación; tampoco generó políticas públicas a favor de la educación democrática, laica, gratuita y pluricultural; mucho menos estableció alguna institución de vigilancia de los procesos electorales y su salvaguarda de los intereses fácticos. Por lo tanto, pensaríamos que fue un movimiento carente de logros y sin repercusión alguna.

En Brasil, el Movimento Passe Livre (MPL), por su parte, logró revocar el intento de aumento de 20 centavos al transporte público en junio de 2013 y obtuvo una victoria al establecer el pase gratuito para algunos sectores estudiantiles. Sin embargo, estos alcances fueron revertidos en los siguientes años, con otros aumentos al transporte a partir de 2015 y la disminución de los accesos gratuitos para estudiantes en 2017, dejando entonces en 
duda las victorias obtenidas por el MPL. Las jornadas de junio de 2013 no lograron estabilizar los aumentos inflacionarios en el transporte público, tampoco fue posible establecer la tarifa zero (acceso gratuito) como lo proponía el movimiento, por lo tanto, habría que buscar los impactos y cambios generados de 2013 en otros escenarios.

Si bien las demandas exigidas por estos movimientos difícilmente llegan a repercutir en la labor institucional - que no por ello es imposible-, sus consecuencias habría que buscarlas en otro espacio. El impacto alcanzado por estas experiencias juveniles y políticas se hace presente en la emergencia de subjetivaciones y en las prácticas políticas utilizadas habitualmente por sus integrantes, las cuales transgreden el modo clásico de participación política vía electoral para extender su participación en los asuntos públicos deconstruyendo la cultura política. Dicho de forma más concreta, un punto clave para apreciar los alcances de estos movimientos es "la cultura" generada a través estas experiencias.

De acuerdo con el filósofo Jacques Rancière:

Por subjetivación entenderemos la producción por una serie de actos de una instancia y de una capacidad de enunciación que no eran identificables en un campo de experiencia dado, cuya identificación va entonces de la mano con la reconfiguración del campo de la experiencia $(. .$.

Un sujeto político no es un grupo que "toma conciencia" de sí mismo, se da una voz, impone su peso en la sociedad. Es un operador que une y separa las regiones, las identidades, las funciones, las capacidades existentes en la configuración de la experiencia dada, es decir, en el nudo entre las distribuciones [partages] del orden policial y lo que ya se ha inscrito en ellas de igualdad, por más frágiles y fugaces que puedan ser estas inscripciones (...) Una subjetivación política es una capacidad 
para producir estas escenas polémicas. (Rancière, 1995, pp. 59-66)

Mediante estos procesos de subjetivación, podemos explicar la aparición de movimientos como Passe Livre, \#YoSoy132 y Ayotzinapa, que traspasan las geografías, los estratos sociales, las posturas ideológicas y adscripciones identitarias, integrando una especie de clima social de indignación y una serie de movilizaciones y múltiples demandas que congenian en un mismo lapso. Estos fenómenos transgreden los hábitos de los actores subjetivados, afectando sus experiencias y redefiniendo sus proyectos de vida en diversos de los $\operatorname{casos}^{3}$. Se integran entonces sentidos políticos a sus acciones comunes, al mismo tiempo que se adoptan nuevas prácticas, redefiniendo la delimitación de la política. En opinión del sociólogo Massimo Modonesi (2016):

Este nivel de análisis deberá derivar de (...) una teoría de la subjetivación y acción política, es decir, de la conformación de un sujeto que actúa políticamente, lo cual desemboca eventual pero frecuente y significativamente en la formación de movimientos sociopolíticos, que son una forma específica, particularmente relevante y trascendente, de subjetivación y acción colectiva (...) La acción política puede ser pensada sólo a partir de que coexista con ella una subjetividad política; ambas deben existir simultánea y no secuencialmente en una relación lógica bicondicional: no hay acción sin sujeto, no hay sujeto sin acción. (p. 24)

Reflexionar estas experiencias requiere al mismo tiempo de un análisis de la desmovilización social presente en ellas. Referimos al:

Muchos de los jóvenes participantes de \#YoSoy132 y Passe Livre modificaron sus sentidos de vida y cambiaron el rumbo de sus expectativas profesionales, orientándose a la defensa de derechos sociales y humanos vía otros movimientos juveniles, sociales, ONS, A.C.s, posgrados e incluso candidaturas políticas en el caso del primero. Véase Andrade (2018). 
conjunto de estrategias que implementan las elites dominantes de los Estados Nacionales en alianza con las elites dominantes globales para disminuir las capacidades de acción y reivindicación de los movimientos sociales y limitar las capacidades de organización social con fines de acción colectiva de la población en general. (Celorio, 2016, p. 45)

Pensar en movimientos como Passe Livre, \#YoSoy132, Ayotzinapa, entre otros, precisa de profundizar las intervenciones de contención, represión, vigilancia y mediación de las violencias estructurales y simbólicas. Por lo tanto, cabe inmiscuirse en el papel generado por las instancias estatales, las que, si bien hasta el momento poco han gestionado las demandas y exigencias de estos movimientos, sí han hecho presentes sus intereses de conflictuar con algunas de las prácticas políticas utilizadas por los jóvenes adheridos a estos fenómenos sociales. Al mismo tiempo, es necesario identificar y descifrar el papel de los medios de comunicación hegemónicos, puesto que el manejo de sus contenidos frente a los movimientos sociales tiende a criminalizar y desprestigiar a las protestas, causando impactos negativos en sectores sociales.

A través de la exposición de la condición juvenil presente en América Latina, la comprensión de las subjetivaciones y prácticas políticas de las juventudes y la relación desmovilizatoria emprendida por los actores gubernamentales y la mass media, es posible ofrecer un desplegado de coordenadas analíticas alternativas a las interpretaciones sistémicas de los movimientos sociales. Hacemos mención a movimientos juveniles más en un sentido de desafío a las prácticas y comportamientos políticos y culturales hegemónicos, que a un antagonismo radical del cambio de las estructuras del modo de producción capitalista, sosteniendo de esta forma la relevancia de la cultura política participativa en el proceso de cambio de las sociedades (Valenzuela, 2015). 
Para la argumentación del planteamiento de este artículo se ha realizado un trabajo exploratorio que retoma el material bibliográfico producido en los últimos años sobre diversos movimientos juveniles en México y Brasil. Se ha dado un seguimiento institucional y hemerográfico a las acciones de desmovilización social más contundentes, generadas por las instituciones estatales y la mass media. Al mismo tiempo, fueron realizadas más de 20 entrevistas a profundidad, semiestructuradas, con participantes de los movimientos aludidos ${ }^{4}$, respetando proporciones de género, clase e ideología. Se rescataron también diversos relatos bibliográficos y hemerográficos de los jóvenes participantes. Dichas narrativas enfatizaron los sentires, pensamientos y experiencias subjetivas sobre sus prácticas emprendidas y sobre la violencia institucional y simbólica desplegada. El análisis de estos datos obedeció al análisis crítico del discurso de Teun Van Dijk (1999), enfatizando el discurso dominante en el caso de la mass media y los discursos de los movimientos juveniles como actores críticos y antagonistas.

El postulado hipotético de este trabajo se orienta a exponer que las repercusiones generadas por los movimientos como \#YoSoy132, acciones por Ayotzinapa, Passe Livre, \#TodosSomosPolitecnico, secundaristas, entre otros, son las subjetivaciones políticas consolidadas y emergidas coyunturalmente, así como la desmovilización social estructural y mediática que criminaliza y reprime a los movimientos juveniles.

\section{Vislumbrar la condición juvenil}

Llegar a entender la diversidad de las manifestaciones emprendidas por miles de jóvenes identificados con los emblemas, demandas, exigencias y prácticas de los recientes movimientos

$4 \quad$ Este artículo se sostiene en la totalidad de las entrevistas realizadas, aunque sólo rescata textualmente algunos de sus relatos. El total del acervo puede consultarse en Andrade (2018). 
sociales resultaría inconcebible si no se realiza un esfuerzo por conocer el escenario social, económico, cultural, histórico y político en el que se desenvuelven.

Orientar las reflexiones dentro de este marco coyuntural permite acercarnos al objeto analizado desde su génesis. Para la comprensión de los movimientos sociales aquí analizados se torna necesario distinguir la clasificación en las juventudes generada por la semilla neoliberal implantada en naciones latinoamericanas en los años 70. Tras el transcurso de poco más de cuarenta años de políticas neoliberales se ha profundizado la demarcación entre una población minoritaria económica, social y políticamente posicionada y beneficiada, frente una cantidad mayoritaria carente de oportunidades, adquisiciones, beneficios sociales y expuesta a las peores atrocidades de las violencias que acompañan los imperativos del libre mercado. Mientras los minoritarios jóvenes pertenecientes al primer tipo disfrutan las ventajas del neoliberalismo, la mayor parte de las juventudes se ven inmiscuidas en un escenario de sobrevivencia, donde el presentismo constituye su principal preocupación y sus sueños y esperanzas se ven cada vez más anubarrados (Valenzuela, 2009).

De acuerdo con diversas investigaciones realizadas por la Organización para la Cooperación y el Desarrollo Económico, América Latina tiene una población joven (15 a 29 años) de 163 millones de personas. De esta cantidad, 30 millones no estudian, no trabajan, ni reciben capacitación. En la mayoría de los países de América Latina menos de la mitad de los jóvenes latinoamericanos de entre 15 y 29 años se encuentran escolarizados. La tasa de escolarización de este sector en 2014 contabilizó 37,4 puntos porcentuales en Argentina; 22,5 en Brasil; 25,6 en Colombia; 43,9 en Chile; y 26,3 en México. En el mismo año, diversas naciones latinoamericanas registraron altas tasas de desempleo juvenil, tal cual fue el caso de Argentina con 14,0; Brasil con 13,5; Chile con 14,6; Colombia con 15,0; y México con 7,7 (OCDE/CEPAL/CAF, 2016). 
Para el caso específico - pero no diferenciado- mexicano, esta división dicotómica adquirió mayor presencia mediática tras el desatinado e irónico acrónimo del "NINI", es decir, la etiqueta peyorativa que evidenció a los miles de jóvenes que NI estudian NI trabajan. Esta etiqueta, incómoda pero reveladora, dejó en entredicho, más allá de su "gracia", la demarcación entre los jóvenes beneficiados y los numerosos excluidos. En el mes de noviembre de hace cuatro años la OCDE presentó el informe Panorama de la Educación 2015, el cual reveló que México mantuvo 7,5 millones de jóvenes que no estudiaban ni trabajaban (OCDE, 2015). En una nación cuya población estriba en 119 millones 530 mil 753 personas, y de la cual 29,5 millones son jóvenes, la cifra resulta alarmante (INEGI, 2013).

El Estado benefactor en América Latina, replegado y sustituido por la apertura al capital externo, las privatizaciones y la reducción del gasto público, colocó a la mayoría de las juventudes frente a un proceso de descapitalización institucional, en el cual millones de jóvenes fueron excluidos de las instituciones estatales formadoras de sentidos y garantes de activos de construcción y mejora de vida, tal cuales son las familias, las escuelas, las empresas, los partidos políticos, los sindicatos, etc. Estos jóvenes se han visto alejados de estas instituciones otorgantes y formadoras de sentidos sociales, motivo por lo cual han encontrado su formación y sentir con otros actores y en otros espacios afectando sus destinos sociales. Como bien señala la antropóloga Rossana Reguillo (2013): “La precariedad no solo es estructural, sino también vital, subjetiva. La inestabilidad y contingencia de muchos de los procesos estructurales marcan los límites y definen el horizonte posible para construir una biografía, un yo". (p.137).

De cara a esta condición estructural, que niega el otorgamiento de elementos económicos, políticos y simbólicos al grueso de las juventudes, aparece el crimen organizado, el narcotráfico y la paralegalidad, las cuales figuran como una alternativa de dotación de sentidos para la construcción de miles de jóvenes desapegados de los márgenes legales e institucionales (Reguillo, 2010), 
lo cual genera un escenario de violencias, discriminaciones, encarcelamientos y muertes para estos jóvenes.

En países como Colombia, México, y Brasil, la insuficiente oferta laboral y educativa ha orillado a miles de jóvenes a las filas del crimen organizado y el narcotráfico. Estos sectores ilegales se han convertido en ofertadores de trabajo y sentidos para miles de jóvenes. Los carteles de drogas suelen reclutar a sus sicarios en las filas de jóvenes precarizados entre 15 y 20 años:

La vida del narco es un ejemplo para ellos, aspiran al poder económico y al reconocimiento del grupo al que se han integrado (narcotráfico); su inexperiencia se muestra en la excesiva violencia que ejercen con sus víctimas y la vida útil de los nuevos reclutas es muy corta dentro de una organización de este tipo, son asesinados por los integrantes de una organización antagónica o los meten a la cárcel. (Reguillo, 2010, p. 407)

De igual manera, estos jóvenes encuentran una opción de sentido en la paralegalidad. A través del comercio informal y el autoempleo en las calles se ganan la vida, arriesgando su seguridad y sus libertades frente a los marcos legales. No sorprende que en América Latina 6 de cada 10 jóvenes que consiguen trabajo, lo encuentran en empleos informales (OIT, 2013). En 2014 las tasas de informalidad en el mercado laboral para jóvenes mantuvieron cifras elevadas. Argentina mantuvo una tasa de 49,1; Brasil de 28,5; Chile de 18,6; Colombia de 47,5; y México de 69,5 (OCDE/ CEPAL/CAF, 2016).

El conjunto de estas limitadas condiciones sociales atrofia el desarrollo social de millones de jóvenes en América Latina, quienes han demostrado un ascendente interés por las condiciones estructurales necesarias para su capitalización de sentidos y recursos, conllevando cada vez más a la exigencia de sus derechos sociales y políticos. Naciones como México, Brasil, entre otras, han experimentado en los últimos años la efervescencia de oleadas de jóvenes enardecidos frente a este escenario tan nocivo. 
En los movimientos como \#YoSoy132, \#TodosSomosPolitecnico, Secundaristas y Passe Livre, es difícil delinear una composición de clase social, ya que en ellos figuran diversos estratos populares y de clase media. No obstante, lo que sí es apreciable es que sus motivos de movilización obedecen a patrones gubernamentales autoritarios (imposiciones y represión), manipulación mediática (criminalización) y golpes económicos (aumentos en el transporte y desvío de fondos educativos), que no sólo afectan a los estratos económicos más desfavorecidos, sino que cada vez más dañan a los jóvenes de clase media, inmersos en el desempleo, salarios insuficientes y escuelas públicas y privadas. Las movilizaciones por Ayotzinapa, en cambio, competen tanto a sectores rurales como citadinos, padres de los desaparecidos y agentes solidarios de diversas regiones, géneros, edades y estratos sociales; sin embargo, una fracción juvenil cobró importancia al aglutinar un movimiento asambleario, interuniversitario y de escuelas de educación media públicas y privadas, que reaccionaron a la represión estatal contra los 43 normalistas desaparecidos y los 6 asesinados en Iguala Guerrero.

\section{Subjetivación y movimientos juveniles}

En el trascurrir del siglo XXI las voces de diversas juventudes han emergido inesperadamente ante la visibilidad de las sociedades en el mundo, mostrando sus nuevas y tradicionales formas de hacer política, al calor de la indignación ante la depredación de un sistema mundializado. El desempleo, la arbitrariedad, la represión, la precariedad y la exclusión social figuran para este siglo como las causas necesarias para que diversas juventudes concientizadas y politizadas abanderen el escudo del hartazgo y salgan a las calles a extender sus malestares, sus frustraciones y su intolerancia ante la condición social del despliegue neoliberal.

Movilizaciones recientes, como el 15-M; Passe Livre; Occupy Wall Street; \#YoSoy132; Ayotzinapa, etc., representan algunas de 
las movilizaciones políticas juveniles en oposición a las diversas coyunturas sociales y políticas, a la vez que a los mecanismos tradicionales de participación política ${ }^{5}$. El emerger de estos movimientos exhibe la afectación directa a sus derechos sociales, como la educación y movilidad (en encarecimiento), los altos grados de represión y violencia, y las acciones antidemocráticas gubernamentales, que han representado motivos suficientes para su aparición en el escenario político, exponiendo que las complejidades económicas y políticas globales no sólo se direccionan a los sectores más desfavorecidos, sino que la precarización avanza hacia las clases medias.

Estas oleadas de movimientos, tanto en México como en Brasil, tuvieron sus expresiones más álgidas en 2012 y 2013, con los movimientos \#YoSoy $132^{6}$ y Passe Livre ${ }^{7}$, los cuales generaron subjetivaciones políticas en centenas de jóvenes, quienes compartieron los malestares de la imposición de un candidato presidencial y del aumento al precio del transporte. Al calor de las coyunturas, estas movilizaciones consolidaron actores políticos, amistades y redes sociales que más tarde serían rearticuladas en otras coyunturas como la Asamblea Interuniversitaria (AI) por Ayotzinapa y el movimiento \#TodosSomos Politecnico ${ }^{8}$, en México 2014, y de

\footnotetext{
5 No damos por determinado que estos movimientos hayan sido integrados en su totalidad por actores juveniles. Reconocemos su heterogeneidad de clase, etaria, gremial, étnica, de género e ideología. Sin embargo, nos concentramos en sus protagonismos e impulsos juveniles, sin cuya presencia y acciones no hubiesen sido los mismos.

6 Surge a raíz de la oposición de jóvenes de universidades y preparatorias privadas y públicas frente a la oposición mediática de Enrique Peña Nieto (EPN) como presidente nacional en 2012.

7 Movimiento fundado en 2005 en Brasil, Porto Alegre, detonante de las protestas de junio de 2013 en la ciudad de São Paulo y en Brasil por el aumento de 20 centavos a la tarifa del transporte público. Véase VV.AA. (2014).

8 Aparece como respuesta a la imposición arbitraria de un reglamento general en el Instituto Politécnico Nacional (IPN), que pretendía tecnificar su enseñanza; aglutinó a todas las escuelas superiores y preparatorias del Instituto.
} 
los secundaristas ${ }^{9}$, en Brasil 2015, los cuales congeniarían a estos jóvenes con nuevas generaciones enardecidas y subjetivadas.

Los procesos de subjetivación política no solo requieren de articulaciones de cadenas autoorganizativas en redes sociales y dispositivos móviles, sino también de la indignación, la ira, la rabia y otras emociones como primer elemento. Como bien lo ha destacado el sociólogo Manuel Castells, son con certeza estos sentires los que orillan a los sujetos a enfrentar el miedo y a desafiar al poder dominante, pese a los peligros implicados. En sus palabras:

(...) los movimientos sociales no surgen sólo de la pobreza o de la desesperación política. Requieren una movilización emocional desencadenada por la ira contra la injusticia flagrante y por la esperanza de la posibilidad de un cambio como resultado de los ejemplos de los levantamientos que han tenido éxitos en otras partes del mundo; cada revuelta inspira la siguiente transmitiendo en red imágenes y mensajes a través de internet. (Castells, 2012, p. 211)

La indignación sin duda alguna ha sido una constante en este ciclo de movilizaciones. La reacción individual y colectiva frente actos de desprestigio, manipulación social, y los diversos actos de violencia estructural, económica, y física, se ha tornado en el punto crucial que ha hecho emerger los posicionamientos antagonistas y las manifestaciones de miles de jóvenes en diversas geografías.

Rodrigo Serrano, estudiante de la Universidad Iberoamericana (Ibero) en el año 2012 y miembro del movimiento \#YoSoy132, me recuerda en una entrevista su malestar durante el 11 de mayo, cuando el candidato presidencial Enrique Peña Nieto (EPN) acudió a su universidad y fue cuestionado por diversos jóvenes so-

\footnotetext{
El movimiento secundarista emergió en septiembre de 2015 por el anuncio del Estado de São Paulo de realizar una reorganización escolar de las escuelas estatales. Véase Campos, Medeiros y Ribeiro (2016).
} 
bre los actos represivos y las violaciones a los derechos humanos del pueblo de San Salvador Atenco ${ }^{10}$ en 2011:

Muchos de mis amigos fueron los que convocaron originalmente a las protestas durante la presencia de los candidatos. Cuando sucede lo de Peña Nieto yo no participo en las protestas. Yo las estoy siguiendo desde mi oficina porque estudiaba y trabajaba. Lo estaba siguiendo en internet. Me informé mucho siguiendo las redes. Y cuando empieza a darse todo el contraataque mediático me indigno mucho. El momento que más me indigna es cuando José Carreño con López Dóriga, a las dos de la tarde en "Radio Fórmula", dice que eran estudiantes entrenados en Atenco, porque tenían claramente técnicas atenquistas $^{11}$. Eso me enoja mucho porque, además, José Carreño es maestro de la universidad y de la carrera de comunicación, que eran los que organizaron la mayoría de las protestas. (Rodrigo Serrano, comunicación personal, 21 de marzo de 2017)

De igual modo, Luca Fesur, integrante del Movimiento Passe Livre, me aclaró en entrevista que la indignación social y subjetiva no es necesariamente coyuntural en las urbes brasileñas, tampoco es un sentimiento que se genera solo en las redes sociales para después tornarse manifestación callejera, sino que es permanente y está presente en la cotidianeidad de habitar y enfrentar las complejidades de movilidad en las grandes ciudades:

No es una cosa que dependa solo de los medios. Es importante subrayar eso. A pesar de hablar mucho de que los medios lo hicieron, ¡no es así!, es más bien un problema político. No hay que hacer una dicotomía entre virtual

\footnotetext{
10 El pueblo San Salvador Atenco, organizado en el "Frente de Pueblos en Defensa de la Tierra", sufrió la represión del Estado en día 4 de mayo de 2006 por oponerse a la construcción de un nuevo aeropuerto en el Estado de México.

11 El calificativo de "atenquistas" alude al pueblo de San Salvador Atenco.
} 
y real, porque lo virtual está ahí en nuestra vida, la gente está superconectada. Pero al mismo tiempo es un problema que tú enfrentas todos los días, al tardar para llegar al trabajo, al pagar la tarifa cara. Eso motivó mucho más, estalló en 2011 e hizo que la gente ganara en 2013. Eso hace que las personas vayan a las protestas y se movilicen, no es el Facebook. La gente tiene un Facebook bonito en la medida de lo posible, es una herramienta importante porque ayuda a las personas a congregarse y juntarse alrededor de la pauta, pero la pauta está en el día a día. (Luca Fesur, comunicación personal, 20 de septiembre de 2016).

Este malestar latente logra potenciar acciones y sentires colectivos que se hacen presentes en momentos de tensión, tal cual lo demuestran diversos estudiantes y académicos del Colegio de México, al emitir un posicionamiento colectivo tras las declaraciones de la Procuraduría General de la República (PGR) que, en voz de su titular Murillo Karam, anunció públicamente los pormenores del asesinato de los 43 jóvenes normalistas desaparecidos el 26 de septiembre de 2014, enfatizando la quema de sus cuerpos y evidencias en un basurero de Cocula ${ }^{12}$ :

La forma en que la información ha sido presentada a los familiares y a la sociedad es condenable. El montaje discursivo de la Procuraduría General de la República es contradictorio: la lógica oficial alienta, sin comprobar, la idea de que los normalistas fueron salvajemente asesinados, pero su conclusión es que continuarán en calidad de desaparecidos. Estamos convencidos de que la presentación de argumentos y materiales no concluyentes y contradictorios tiene como único fin desmovilizar las acciones de protesta. Asimismo, el gobierno mexicano y sus instituciones se han mostrado indolentes ante la

12 Pueblo mexicano del Estado de Guerrero, ubicado en la región Norte de dicha entidad. Es cabecera del municipio homónimo. 
situación emocional de los familiares de los 43 normalistas y, en distintos momentos, han promovido especulaciones de diversa naturaleza, abonando al tratamiento sensacionalista del caso (...)

Ante estas circunstancias, reivindicamos el derecho a la movilización social pacífica y solidaria, sostenemos el dolor que hoy sentimos colectivamente y exigimos justicia. No permitiremos que las provocaciones lanzadas desde distintos niveles de gobierno, ya sea de manera frontal o a través de grupos de choque a su servicio, nos detengan, como han intentado hacerlo en manifestaciones recientes. Exigimos un alto total e inmediato a las hostilidades del gobierno, a las detenciones arbitrarias, a las amenazas, a la represión en cualquiera de sus formas, a la criminalización de la protesta social y a cualquier otro intento por inhibir el derecho a la libre expresión de la ciudadanía. (Red Política, 2014)

Nos encontramos sin duda alguna frente un "resquebré" de prácticas tradicionales de participación política, las cuales ya no satisfacen ni representan a miles de jóvenes en el mundo. Aludimos a las formas institucionales y de tradición moderna, como las afiliaciones y trayectorias en partidos políticos, ONG y sindicatos, así como a la emisión del voto en campañas electorales (Del Águila, 2002), las cuales pierden sentido en partes de las generaciones del siglo XXI, profundizando una crisis de representatividad que sólo es resarcida con la participación directa de las mismas juventudes que, en experiencias como las ya mencionadas, construyen espacios de convivencia y participación política en escenarios desfavorables.

Esta crisis de representatividad no sólo es percibida por las juventudes actoras como carencias de espacios y temáticas de intereses juveniles en los partidos políticos, sindicatos, e instituciones gubernamentales, sino que también representa un hartazgo con los procesos de corrupción, cooptación, antidemocracia 
y represión presente en las últimas décadas, trastocando de esta manera tanto a gobiernos progresistas como conservadores.

En Brasil, los integrantes del Movimiento Passe Livre, Caio Martins y Leonardo Cordeiro, han aludido a este conflicto de la siguiente forma:

Ahora bien, el llamado trabajo de base desde hace años ha desaparecido de la práctica política de la izquierda brasileña. La organización popular, que era la base de la izquierda, fue el costo del proyecto del gobernar gestado por ésta a finales de los años 70 - fue un precio pagado a medida que ese proyecto se realizaba. Al ascender hacia el gobierno, el PT alza consigo la dirección de los movimientos populares y la inserta plenamente en los mecanismos de la gestión de los conflictos sociales (de los canales gubernamentales de "participación" al "Tercer Sector" en expansión) (...) la tónica del discurso es la de la inclusión. Marcadas por una creciente distancia entre la cúpula y la base, encuadradas en las "políticas públicas" (desarrolladas a partir del conocimiento acumulado por los propios militantes), las organizaciones populares sufren un vaciamiento que las atora a una enorme máquina burocrático-electoral. Las "bases", ahora, sólo pueden existir como contingentes cosificados, debidamente domesticados y representados, de trabajadores - tratados como moneda de cambio de las burocracias. (Martins y Cordeiro, 2014, traducción propia)

En México, Joel Ortega miembro del movimiento \#YoSoy132, me refirió en una entrevista el mismo sentimiento con estas palabras:

A mí la consigna que más me gustaba del movimiento era la de por una democracia auténtica. Porque yo sentía y siento todavía que las opciones electorales que hay no me satisfacen. Finalmente todos los partidos con matices tienen mecanismos clientelares y son autoritarios (...) En- 
tonces había que hacer otra y esa otra fue el movimiento 132 momentáneamente. Si decíamos que éramos apartidistas, no podíamos ser igual que los partidos políticos de autoritarios. Entonces había que hacer un movimiento democrático. (Joel Ortega, comunicación personal, 16 de febrero de 2017)

A través de estas narrativas, no es complejo percibir que los repertorios de acción y organización adoptados por estos movimientos representan una posición de rechazo y repelo de las formas institucionales de hacer política, propias de las instituciones representativas. Los movimientos juveniles del siglo XXI optan por construir acciones democráticas mediante su participación directa y de principios como la autonomía, la horizontalidad y el apartidismo.

$\mathrm{Al}$ interior de estas experiencias es constante observar cómo el uso de las redes sociales figura como herramienta de información, diálogo, divulgación, organización y convocatoria de las juventudes, para manifestarse socialmente ante las inconformidades económicas, sociales, o políticas. Sin embargo, estos movimientos no pueden ser minimizados por su uso tecnopólítico ${ }^{13}$, sino que existen en ellos más elementos que resaltan a la luz como prácticas políticas contrahegemónicas.

Estas movilizaciones adquieren una conformación heterogénea, ya que participan distintas capas sociales e ideológicas que encuentran compatibilidad en sus fines. Surgen de manera coyuntural y emergente, y pretenden ejercer una horizontalidad en su toma de decisiones a través de asambleas locales y generales, tal cual lo representan la Asamblea General Interuniversitaria del \#YoSoy132 (AGI), la Asamblea General Politécnica (AGP), la Asamblea Interuniversitaria pro Ayotzinapa (AI) y el Comando

\footnotetext{
13 Entendemos a la tecnopolítica como el uso táctico y estratégico de las herramientas digitales en identidades colectivas online para la organización comunicación y acción colectiva (Toret, 2013).
} 
de Escuelas Ocupadas de los secundaristas; fomentan una coordinación colectiva, debido a que, durante su organización, diversos integrantes forman parte de las coordinaciones y asumen representaciones temporales, evitando liderazgos.

Sus espacios de acción se direccionan a diferentes puntos de aglomeración según la magnitud e intención de las convocatorias. Se declaran discursivamente ajenas a los partidos políticos y construyen un malestar político colectivo. A través de estrategias culturales, realizan prácticas políticas que encuentran en el arte (proyecciones, bailes, conciertos, performance, murales etc.) su modo de expresión e información, tal cual lo expresan las proyecciones de documentales sobre la violencia policial en las favelas de los secundaristas, los performances callejeros y batucadas del MPL y el surgimiento del Colectivo de Artistas Aliados del \#YoSoy132, el cual aglutinó a diversas escuelas de arte encargadas de realizar esas y otras acciones culturales. De igual forma, usan y transforman sus cuerpos, decorándolos, alterándolos, desnudándolos y construyendo con ellos una resignificación de índole y contenido político.

La emergencia de estos movimientos juveniles representa una propuesta alternativa en marcha de empoderamiento político y participación popular en los asuntos comunes. Los jóvenes involucrados construyen su subjetividad política en la marcha de las coyunturas y a través de sus prácticas contrahegemónicas y redes de activismo.

Estas experiencias marcan también un distanciamiento de los movimientos tradicionales partidistas, sindicales, gremiales etc., al no pretender allegar a las instituciones de gobierno y controlarlas, tampoco presentan un proyecto político o pliego petitorio que los induzca a mantener una directriz de demandas concretas en busca de beneficios particulares. Por lo contrario, su efervescencia los coloca en las calles sin ninguno de estos procedimientos. De acuerdo al planteamiento del politólogo Benjamín Arditi, estas experiencias no requieren de un plan o proyecto político; es un acto injusto exigirles alguno, puesto que actúan más como insurgencias 
que como iniciativas programáticas, en sus propias palabras: "las insurgencias buscan perturbar el statu quo mientras que los programas quieren gobernarlos" (Arditi, 2015, p. 59).

A través de sus principios y sus estrategias tecnopolíticas y culturales, estos movimientos buscan interactuar con la sociedad más que con las instituciones gubernamentales, intentando comunicar su indignación y modos de acción como vehículo del despertar de nuevas subjetivaciones. De esta manera podemos apreciar que, más allá del impacto sistémico que estos movimientos puedan lograr, existe un potencial cultural capaz de transgredir sentires, pensamientos y hábitos sociales. Como bien afirma el sociólogo Manuel Valenzuela (2015): “Así, los movimientos sociales buscan influir en la configuración de nuevos modelos culturales o mejor aún de crear nuevos modelos" (p. 33). Por tales razones, resulta impreciso catalogar a estas movilizaciones como "movimientos estudiantiles", ya que no se encuentran limitadas por barreras sistemáticas, sino que, al pretender alcances culturales-políticos, resulta más atinado referirse a ellas como "movimientos juveniles" (Foracchi, 1972).

Experiencias como las aquí mencionadas nos abonan elementos para comprender la construcción de una nueva articulación entre la reapropiación de espacios públicos y la creación del ejercicio de alternas relaciones de poder (que ponen sobre el escenario los grandes conflictos políticos y económicos, como la precariedad, el desapego institucional —vivienda, salud, empleo educación-, la democratización de las instituciones, el cese a la impunidad, la discriminación, criminalización, desaparición forzada, guerras y asesinatos) con las instituciones estatales en vías de la colocación de una agenda política alternativa de expresión de las juventudes.

No obstante, esta aspiración ha encontrado diversas barreras, como la criminalización, represión y persecución de las protestas y de sus participantes, las cuales, más que conectar las temáticas de interés de estos sectores juveniles tienden a desmovilizarlos, impidiendo un circuito favorable de diálogo y fomentando la 
imposición unilateral de la agenda pública y la violación de los derechos políticos y sociales de los actores.

\section{Desmovilización estructural}

Encontrar una respuesta de pretensión objetiva que atienda a la interrogante de qué ha sucedido con los movimientos y movilizaciones juveniles de los últimos años frente al aparato estatal, requiere de prestar atención a los actos institucionales legales (leyes, iniciativas, decretos, políticas públicas, sentencias, etc.), al mismo tiempo que a las medidas metalegales y de facto que se implementan con mayor cautela.

Diversos países en la región latinoamericana han impulsado una serie de estrategias direccionadas a la desmovilización de la sociedad de los últimos años. Como primera instancia, cabe llevar la atención a algunas medidas impulsadas indirectamente desde los artificios legislativos.

En el caso mexicano, ha figurado principalmente la Ley Telecom, definida en los medios como la "Ley Stalker", en cuyos artículos 189 y 190 se otorga licencia a las autoridades para acceder a los metadatos ${ }^{14}$ de los usuarios, violando el derecho a la privacidad. Está presente también la Ley de movilidad de la Ciudad de Méxi$\mathrm{co}$, que pretende regular las formas de realizar una protesta social restringiendo la libertad de expresión y reunión, o la iniciativa de reforma a las Leyes de la Propiedad Industrial y Federal del Derecho de Autor, mejor conocida en la jerga como "Ley Beltrones" que, mediante el eufemismo de la protección industrial y el combate a la piratería, implementa también la censura y detiene la difusión

14 Los metadatos son todos aquellos datos de los datos generados en el uso de los dispositivos tecnológicos de comunicación. Estos incluyen el origen, destino, duración, fecha, hora y ubicación de cada una de las acciones que realizamos con los dispositivos de comunicación (llamadas, tuits, publicaciones, RTs, fotografías, videos, conexiones, etc.). Estas bases de metadatos pueden ser utilizadas para revelar aspectos sensibles sobre la vida privada de las personas. 
cultural realizada por millones de internautas. De igual forma, podemos pensar en la iniciativa de la Ley Federal para Prevenir y Sancionar Delitos Informáticos, mejor conocida como "Ley Fayad", que busca prevenir y sancionar los delitos informáticos, pasando por alto la privacidad de los internautas y criminalizando diversas actividades usuales en la red y los sistemas operativos.

En el caso brasileño ha figurado el Marco Civil de internet que, al igual que la "ley Stalker", establece en sus artículos 10 y 15 la entrega de contenidos privados (metadatos) a las autoridades judiciales, posibilitando atentados contra la libertad de expresión. Figura también el uso ilegal de la Lei da organización criminoza y la Lei de drogas, que han servido como sostén para realizar actos de infiltración y detención durante protestas sociales (Araújo, 2016), y la Lei de terrorismo que, bajo la premisa del resguardo social contra el terrorismo, implementa una vigilancia física y virtual en los actos de manifestación política.

Una segunda instancia para relacionar la labor institucional con las prácticas políticas de miles de jóvenes, radica en direccionar la investigación a las estrategias de acción que el Estado y sus miembros llegan a implementar debido a la incomodidad generada por diversas de las acciones políticas contemporáneas.

Hasta el momento se han visibilizado algunas medidas implementadas por el Estado que, si bien no responden al marco institucional que la legislación les brinda, sí llegan a considerarse como acciones directas contra las formas de hacer política contemporánea. Cabe recordar las acciones del "Grupo Relámpago", aquel grupo de policías vestidos de civil que realizó detenciones arbitrarias a jóvenes durante los desmanes ocurridos el $1^{\circ}$ de diciembre de 2012 ${ }^{15}$, y las jornadas por Ayotzinapa en 2014 que continuarían posteriormente, o la publicación en la Gaceta oficial de la Ciudad de México del 25 de marzo que se refiere al Protocolo de

151 de diciembre de 2012 (1DMX), día de toma de protesta del candidato electo Enrique Peña Nieto. Véase Servín (2012). 
Actuación Policial de la Secretaria de Seguridad Pública del Distrito Federal para Control de Multitudes (PCM), el cual autoriza a la policía capitalina para utilizar la violencia en contra de los manifestantes que considere agresivos.

En el caso brasileño figura la presencia de los agentes policiales infiltrados conocidos como "P2", los cuales realizan actos de infiltración tanto en las plataformas sociales de organización como en las asambleas y protestas de los manifestantes, realizando decenas de detenciones arbitrarias. No causa extrañeza que, a partir de las movilizaciones de \#YoSoy132 y Passe Livre, en ambas naciones existan organismos facultados para la vigilancia en las redes sociales, como la Policía Cibernética de la Ciudad de México y la Agencia Brasileira de Inteligencia.

La operatividad de estas policías encubiertas ha causado diversas detenciones arbitrarias y violaciones a los derechos políticos de las juventudes (libertad de expresión, principalmente). Movilizaciones en Brasil, como las convocadas por el MPL, Não vai ter copa y el movimiento de los secundaristas, han sido blanco de estos actos desmovilizatorios.

Uno de los acontecimientos más visibles de estas acciones ocurrió el 23 de junio de 2014 en la ciudad paulistana, durante las protestas contra la Copa del Mundo, cuando las fuerzas policiales detuvieron arbitrariamente al profesor Rafael Lusvarghi y al estudiante y funcionario de la USP Fábio Hideki. Ambos manifestantes fueron acusados de portar explosivos, incitar a la violencia, resistir a la aprensión, desacato de autoridad y realizar asociaciones criminales armadas, bajo el argumento de que portaban gasolina y artefactos incendiarios. $Y$ aunque ambos manifestantes negaron los cargos, fueron encarcelados por decreto preventivo y liberados después de un largo proceso al no encontrar elementos de acusación (Rosati y Souza, 2014).

De igual modo, estos actos han sido repetidos con las movilizaciones de los secundaristas, quienes han padecido sus primeras 
experiencias de detenciones arbitrarias como menores de edad en actos públicos. Durante las ocupaciones escolares de 2015 en el Estado de São Paulo, diversos estudiantes comenzaron a ser monitoreados y perseguidos, tanto al interior de las instalaciones como fuera de ellas, por las direcciones de las escuelas y la Policía Militar, la cual no siempre se identificaba. Durante la ocupación del Centro Paula Souza, como estrategia de la exigencia de aclaración del desvío de fondos para la alimentación en las escuelas técnicas, diversos estudiantes fueron intervenidos por agentes militares, quienes los amenazaron e intimidaron para no volver a movilizarse. De igual manera, algunas jóvenes denunciaron agresiones sexuales por parte de la policía (Acayaba, 2016).

A propósito de estas acciones de vigilancia e intimidación, la activista Laura Frare, integrante del movimiento de los secundaristas, relató en una entrevista:

Desde 2013 han pasado persecuciones informales, porque no son legales pero la policía las hace. Empezaron a pasar con los grandes movimientos como MPL, pero yo creo que de formas distintas, ahora un poquito más sofisticadas, creo que en Brasil ahora vivimos un momento de tensión, y que tiene que ver con la salida de Dilma del gobierno. Creo que tiene que ver con una movilización de cortes, de ajustes fiscales, entonces no quieren que las personas se movilicen tanto, pero están peleando muchísimo por eso (...)

2013 endureció a la policía definitivamente, bueno endurecer no, porque siempre fue dura. La cuestión es que ahora saben cómo lidiar con los movimientos sociales. Incluso después de las ocupaciones del año pasado saben cómo no reprimir con violencia física (...)

Ahora lo que hacen son persecuciones muy fuertes. Entonces, algunas personas son marcadas. Yo tenía un amigo que su casa fue invadida dos veces por policías en la misma semana. Sus amigos fueron intervenidos por 
policías buscando información sobre dónde está él, les mostraron algunas fotos de él en el celular. Esto que pasó con el militar infiltrado en un grupo de Whatssapp ${ }^{16}$ fue un shock muy grande, porque hay muchas historias de que esto pasaba, pero nunca había pasado de manera tan explícita, y era real. En el gobierno de Dilma aprobaron la Ley antiterrorismo, que legitima e institucionaliza esta cuestión de detenciones preventivas. Es una cosa que es muy difícil porque las personas tenemos mucho miedo, porque empieza a haber amigos detenidos por la policía en la calle durante las manifestaciones, pero también en las calles de sus casas.

O el joven interrumpido y agredido por la policía dentro del metro. La policía tenía toda una carpeta de información sobre su persona y sus actividades ${ }^{17}$. Por supuesto que ocurrió y fue por Facebook. Lo que vimos desde el principio fue que la policía realizó un delito. Le pegaron, lo torturaron. Yo lo conocía, incluso lo ayudé con esas cosas del caso, fue un lío muy grande de cuestiones legales pero también políticas, de decidir si va a seguir o no por precaución y seguridad. Es miedo, una situación de tensión de que estamos siendo observados todo el tiempo, entonces muchas personas creen que están siendo perseguidas. Y sí, a veces lo están y otras no, pero no importa $(. .$.

\footnotetext{
16 Se refiere al caso de un agente policial infiltrado, quien se hizo pasar por reportero en las redes sociales con cuentas falsas bajo el nombre de "Balta Nunes", y tras concluir una asamblea de los secundaristas propuso a estos salir del centro cultural. Al dirigirse a un acto en contra de los juegos paraolímpicos, los estudiantes fueron interceptados y detenidos por la policía, quienes les implantaron armas y los trasladaron al Departamento Estadual de Investigações Criminais (DEIC), donde fueron acusados de formación de pandilla y corrupción de menores (Salvadori y Berna, 2016).

17 Véase Milena (2016).
} 
Los policías ahora graban las asambleas y manifestaciones. Eso es una cosa que aprendieron en 2013 y yo creo que mucho en las ocupaciones (...) Esto es terrible porque ellos tienen todas estas fotos, y nosotros sabemos que tienen boletas con fotos de nosotros dentro de las ocupaciones tomadas desde fuera o en manifestaciones. (Laura Frare, comunicación personal, 9 de noviembre de 2016)

Otro punto que resalta de estas medidas fácticas y pragmáticas alude al papel desarrollado por diversas figuras políticas quienes, de no tener alguna credibilidad en el uso de los medios alternativos y las redes sociales, aprendieron a verlos como un campo de trinchera electoral y un medio de construcción y limpieza de su imagen pública. De la manera más discreta posible, diversos políticos contratan empresas de publicidad, las cuales se encargan de generar batallones de cuentas bots que son utilizadas para difundir información deseada por el contratante y pretender generar un cierto tipo de debate respecto de temas políticos, a la vez que sesgar, disminuir y atacar información que dañe su imagen pública, pasando con este acto encima de sus contrincantes y disidentes ideológicos (Melín, 2012).

La utilidad de estas cuentas falsas suele llegar a tomar medidas drásticas, tal cual ha sucedido con los ataques de censura y las campañas de desprestigio a opositores políticos, periodistas, académicos e internautas comunes, hasta el grado de generar intimidación y amenazas de muerte. En este tema, la nación brasileña ha emprendido acciones de amplio alcance, como el bloqueo de redes sociales en todo el país, como aconteció con la plataforma Whatsapp en diciembre de 2015 y mayo y julio de 2016, limitando la comunicación y organización de los usuarios.

Uno de los acontecimientos que demuestran con mayor claridad el uso desmovilizatorio dentro de las plataformas de redes sociales es, sin duda alguna, el padecido por el movimiento de Ayotzinapa en 2014, el cual se manifestó bajo el hashtag \#YaMeCanse, en alusión al mensaje público emitido por el titular de la 
PGR Murillo Karam el 7 de noviembre, en el cual, tras enunciar el asesinato, la incineración y desaparición del delito de los 43 estudiantes normalistas, cerró la rueda de prensa mencionando que ya se había cansado.

Este hashtag, en breve, sería creado y apropiado por miles de internautas, llegando a ser el más usado en el mundo durante las siguientes horas, y perduraría en trending topic durante 26 días hasta el 5 de diciembre, cuando un ataque masivo de bots lo eliminaría del espacio virtual público tras miles de denuncias apócrifas que lo reportaron como spam, logrando que los algoritmos de Twitter lo eliminaran. Este acto, orquestado por más de $50 \mathrm{mil}$ cuentas falsas, fue resistido por la serie de los hastags \#YaMeCanse2, \#YaMeCanse3, \#YaMeCanse4... hasta el \#YaMeCanse20 y demás, que colocaron nuevamente el malestar, la ironía y el reclamo inicial hasta los primeros meses de 2015 (Rovira, 2017).

El desarrollo de estas medidas legales, metalegales y de facto, apuntan a suponer que las subjetivaciones y las prácticas políticas en marcha de diversos jóvenes obtienen como respuesta la criminalización, la censura y la represión. Estos hechos no omiten por nada los intentos de diálogo que los representantes de Estado puedan llegar a tener con diversas movilizaciones juveniles. Cabe recordar para ello las mesas de discusión entre los representantes de la Secretaria de Educación Pública (SEP) y la Secretaria de Gobernación (SEGOB) con los diversos comisionados del movimiento mexicano \#TodosSomosPolitecnico y el diálogo abierto entre la presidenta Dilma Rousseff con el MPL en 2013. Sin embargo, estas acciones de diálogo se presentan al mismo tiempo que las acciones criminalizadoras.

\section{Desmovilización mediática}

El papel de los medios de comunicación frente a las experiencias de movilización juvenil de los últimos años, nos permite apreciar el escenario de violencia simbólica que se orienta a construir imaginarios sociales de las movilizaciones a favor de 
su desvirtuación y desmovilización social. En los trayectos de los movimientos \#YoSoy132, Passe Livre, Ayotzinapa, entre otros, ha sido muy peculiar que algunos de los principales medios de comunicación, como Televisa, TvAzteca, Milenio, Universal, O Globo, A Fohla, O Estado, por mencionar algunos, hayan construido imágenes de desaprobación de los movimientos, centralizando y generalizando su producción de información en actos violentos reprobatorios.

En México, la emergencia causada por el video "131 jóvenes de la Ibero responden"18, editado por estudiantes de la misma institución, que emitieron una respuesta a Joaquín Coldwell (presidente nacional del PRI), Arturo Escobar (coordinador del grupo parlamentario del Partido Verde y vocero nacional del mismo), Emilio Gamboa (líder de la Confederación Nacional de Organizaciones Populares (NOP), y a los medios de comunicación de dudosa neutralidad, quienes habían tergiversado los hechos ocurridos en la visita a la Ibero del candidato a la presidencia Enrique Peña Nieto del día 11 de mayo de 2012 (García Imelda, 2013), permitió contrastar los hechos manipulados mediáticamente. Las televisiones principales hicieron eco en que el abucheo y cuestionamiento al presidente durante su visita fue realizada por porros, acarreados $^{19}$ — por la oposición ¡claro! - y jóvenes atenquistas que solo buscaban dañarlo. Sin embargo, la alta difusión de este video dejó muy en claro que se trataba de estudiantes críticos, politizados y con una buena memoria histórica para relacionar las violaciones y asesinatos ocurridos los días 3 y 4 de mayo de 2006 en San Salvador Atenco, donde el candidato Peña Nieto fungía como gobernador de la entidad federativa.

\footnotetext{
18 Publicado en Youtube, 14 de mayo de 2012. Recuperado el 24 de diciembre de 2018 de https://www.youtube.com/watch?v=P7XbocXsFkI

19 Los grupos porriles son células de choque al interior de las universidades públicas al servicio de partidos políticos. El acarreo responde a la movilización clientelar de bases sociales en apoyo a partidos políticos.
} 
Otro hecho de tergiversación y condicionamiento de información por parte de los medios de comunicación es el acontecido tras la movilización del Instituto Politécnico Nacional (IPN), en 2014. Tras el cierre de todas las instalaciones de esta universidad y la exigencia de estudiantes, trabajadores y profesores de derogar el aprobado plan de estudios impulsado por la directora Yoloxochitl Bustamante, las movilizaciones de los estudiantes del politécnico llegaron a realizar una marcha rumbo a la SEGOB, donde el Secretario de Gobierno Osorio Chong apareció de forma inesperada y dio pie a una serie de diálogos entre el gobierno y los estudiantes. Este hecho causó revuelo en los medios de comunicación masiva, que no hicieron más que posicionar al movimiento \#TodosSomosPolitecnico como un movimiento ejemplar, pacífico y comprensible, es decir un movimiento "políticamente correcto" que dialoga y no enfrenta, ni intransige ${ }^{20}$.

Más tarde, las decisiones aprobadas por la Asamblea General del Politécnico (AGP), que resolvieron no relacionar la tragedia de Ayotzinapa del 26 de septiembre y la masacre de Tlatelolco del 2 de octubre de 1968, dieron pauta para que, ante los medios, el \#TodosSomosPolitecnico mantuviera su buena reputación tras el mérito de su buen comportamiento. Ante estas decisiones asamblearias, diversos medios de comunicación transmitieron variadas entrevistas a representantes del politécnico, recalcando siempre su buen comportamiento ${ }^{21}$ y logrando con ello crear una opinión negativa de los movimientos que se gestaban en las

20 Para ejemplificar esta construcción de imagen positiva mediática, véase “El Mañanero de Forotv" en la red social Youtube, 1 de octubre de 2014. Recuperado de https://www.youtube.com/watch?v=uEkYb-RJEeM

${ }_{21}$ Como ejemplificaciones de diálogo de medios de comunicación masiva y \#TodosSomosPolitecnico y su construcción positiva mediática véase "El Mañanero" con Daniel Antonio Rosales, estudiante de Ingeniería Civil del IPN, en "Noticieros Televisa", Youtube, 29 de septiembre de 2014. Recuperado de https: / / www.youtube. $\mathrm{com} /$ watch?v=HzfUOfNqS0M. Véase también "Cadenatres Noticias", Youtube, 3 de octubre de 2014. Recuperado de https://www.youtube.com/watch?v=IIOqWFziQ. Y véase Adela Micha, Youtube 13 de noviembre de 2014. Recuperado de https://www.youtube.com/watch?v=wuBD3RLIIEE 
mismas fechas, como lo fueron las marchas de exigencia de la presentación con vida de los 43 estudiantes desaparecidos y la conmemoración de los 46 años transcurridos del crimen de Estado en Tlatelolco.

En la experiencia brasileña, los medios de comunicación también han causado un impacto negativo sobre las movilizaciones juveniles. Desde el comienzo de las jornadas de junio de 2013, diversos medios de comunicación hegemónica, como O Estado de São Paulo y Folha de São Paulo, emprendieron acciones de desprestigio del MPL y de los miles de manifestantes. Previo al 13 de junio, día de protesta, habían generado una imagen de violencia de las manifestaciones, atribuyendo a todos los participantes la etiqueta de "revoltosos", por algunos actos radicales que habían acontecido, por lo tanto hicieron pública la exigencia de la respuesta del Estado, llamando así a retomar las avenidas principales.

Este llamado fue escuchado por la Policía Militar de São Paulo, la que emprendió diversas detenciones arbitrarias. Solo que las acciones represivas policiales ya no se dirigieron únicamente a los manifestantes, sino también a los pasajeros de ómnibuses, transeúntes, vecinos y reporteros. En este acto se contabilizaron más de 100 personas heridas y 241 detenciones (Borba, Felizi y Reys, 2014). Entre los múltiples lesionados destacó el caso de la reportera Giuliana Vallone de la Folha de São Paulo, quien sufrió el impacto de una bala de goma en el ojo derecho. De igual forma el fotógrafo freelance Sergio Silva, quien recibió una bala de goma en el ojo izquierdo.

Estos posicionamientos de la mass media en contra de las manifestaciones antisistémicas se han visto direccionados principalmente sobre los sectores juveniles. Muchas de las protestas de los últimos años ha sido calificadas de violentas y relacionadas con los black blocs, aludiendo a los manifestantes de vestimentas oscuras y rostros cubiertos que implementan tácticas violentas contra el capital, tanto en países europeos como africanos y ame- 
ricanos (Dupuis-Déri, 2014). Se ha construido exitosamente una criminalización de la protesta, basada en premisas etarias, sociales y estéticas. Ser joven, precarizado, portar vestimenta popular o cubrirse el rostro con algún objeto, se ha tornado en sinónimo de "sospechoso" de poder realizar actos vandálicos e inclusive terroristas ${ }^{22}$.

Más tarde, en la tensión de las movilizaciones por Ayotzinapa, los principales medios de comunicación crearían un escenario mediático similar al de la ciudad paulistana. Tras las declaraciones sobre el presunto asesinato de los 43 normalistas del titular de la PGR Murillo Karam del día 7 de noviembre, miles de usuarios convocaron inmediatamente a una marcha en repudio a la construcción de la narrativa emitida. Ésta inició a las 20:00 horas en las instalaciones de la PGR y se dirigió sobre Paseo de la Reforma hasta culminar en la plancha del Zócalo capitalino, en donde se aglomeraron cerca de 20.000 manifestantes y más tarde un grupo minoritario incendió la puerta del palacio de gobierno. Este hecho fue seriamente repudiado en los principales diarios, quienes aludieron a estos manifestantes como vándalos, anarquistas, infiltrados, porros y otros calificativos, enfatizando que la manifestación era en su totalidad pacífica y que estos actores más radicales eran ajenos a las protestas (Hernández y Miranda, 2014). De esta manera fue negada la pertenencia de estos manifestantes como integrantes de las protestas, cuyos repertorios de acción son más radicales, logrando así imponer arbitrariamente un tono pacifista a las protestas y polarizarlas con las acciones violentas.

Actos similares serían repetidos durante las protestas por Ayotzinapa, como en la quema de una estación del metrobus dos días antes, o la quema de un automóvil dentro de las insta-

22 En el año de 2014 la Presidenta Dilma Rousseff aprobó la ley de terrorismo, mediante la cual la Agencia Brasileña de Investigación colabora con el Buró Federal de Investigaciones (FBI) y otras fuerzas policiales globales buscando tanto en medios electrónicos como fuera de ellos vínculos y simpatizantes del terrorismo. 
laciones de Ciudad Universitaria (UNAM), tras la detonación de algunos disparos cerca del auditorio Che Guevara del día 14 de noviembre. Estos actos no neutrales, por parte de la mass media, no sólo sesgarían las acciones de los grupos radicales durante las protestas por los 43 normalistas, sino que también invisibilizarían otras prácticas simbólicas, tal cual ocurrió el día 20 de noviembre, cuando algunos jóvenes universitarios incendiaron una efigie de EPN tras concluir una marcha en memoria de la revolución mexicana y por la aparición de los normalistas (Pineda, 2017). Las imágenes de este acto artístico y simbólico serían omitidas en las principales cadenas televisivas, quienes hicieron énfasis sólo en la magnitud de la marcha, evadiendo así el sentimiento y la expresión de descontento social que enarbolaba este acto frente al Estado y el ejecutivo federal. No obstante, estas imágenes serían reproducidas y viralizadas en las plataformas sociales.

La tergiversación de información que suele caracterizar a diversos medios de comunicación masiva pone en entredicho la neutralidad que debería regirlos. Las prácticas políticas desarrolladas por miles de jóvenes contemporáneos se ven en la necesidad de buscar y crear medios alternativos de comunicación, con los cuales transmitir parte elemental de información que visibilice otros relatos, narrativas, datos, experiencias y acontecimientos, para brindar la posibilidad a los receptores de los medios de contar con más elementos para que ejerzan su propia opinión sobre los fenómenos sociales, económicos y políticos de día a día.

La producción y consumo de información mediática representa, ahora más que nunca, una trinchera que disputa la veracidad y credibilidad de los hechos durante las manifestaciones de los últimos lustros. Los movimientos sociales se ven en la necesidad de generar y difundir sus propios contenidos como estratagema de protección de los ataques de la mass media. Acciones tradicionales, como el brigadeo durante las protestas y el trabajo de base, se extrapola ahora a los escenarios virtuales, en los cuales, a través de páginas, revistas, diarios, canales, y cuentas de 
Facebook, Twitter y Youtube, los movimientos sociales ejercen un acto contrahegemónico.

\section{Consideraciones finales}

La reflexión acerca de algunas de las repercusiones generadas por los movimientos juveniles como \#YoSoy132, Passe Livre, \#TodosSomosPolitecnico, Ayotzinapa, entre otros, en relación a los procesos de subjetivación y su interacción con las estructuras estatales y los medios de comunicación, despabila el escenario negativo que permea en el imaginario hegemónico de estos movimientos. A través de estas coordenadas de análisis nos es posible visibilizar una serie de acontecimientos producidos en las subjetividades políticas de los participantes, así como una ola de dispositivos de desmovilización social generadas por algunas de las instituciones estatales y por algunas de las principales empresas de la mass media. Estos actos, en su conjunto, han sido muchas veces invisibilizados en los análisis de movimientos sociales centralizados en las demandas (inputs) y cambios sistemáticos (outputs) (Easton, 1969), por lo que transparentarlos se ha convertido no sólo en un acto de exigencia, sino también en un método de comprensión de los movimientos.

Gran parte de los logros alcanzados por estas movilizaciones se encuentra en las afectaciones de los actores frente a situaciones sociales nocivas, y en la reconstrucción, adaptación y generación de prácticas culturales y políticas que han adquirido y/o reforzado miles de jóvenes participantes de las coyunturas y escenarios políticos de los últimos años, llegando a formar parte en más de uno de ellos. La utilización de la web 2.0, las redes sociales y otras tecnologías como medios de información, discusión, organización y convocatoria, aunada con las actividades políticas en las calles, constituye la actual forma de participación política y ejercicio democrático del siglo XXI. No se trata necesariamente de posturas contrapartidistas y contrasistémicas, sino más bien de alternativas a los modelos políticos sistémicos y la forma de participación po- 
lítica dominante. Dentro del MPL existe un dicho que aclara esta postura: "Somos apartidistas, pero no contrapartidistas" 23 .

Las temáticas abordadas, las múltiples exigencias, la indignación emergente de estas juventudes, apuntan a la construcción de una agenda política alternativa y legítima que busca reproducir en propia voz de los afectados otro escenario social y otra forma de hacer política. La adopción de principios como la autonomía, el apartidismo, la horizontalidad, entre otros, es muestra clave de qué tipo de política es la que está en disputa, así como también representa qué tipo de sociedad es la que están construyendo las recientes generaciones juveniles.

Estados como el mexicano, el brasileño y los principales medios de comunicación en ambos países, se muestran en determinadas ocasiones como barreras para esta propuesta de cambio social. Sus diversos mecanismos de respuesta obnubilan el potencial de la propuesta cultural y política emprendida por estas movilizaciones juveniles, logrando con ello profundizar la criminalización juvenil, las desigualdades sociales, la corrupción, la vigilancia social, el espionaje, la represión y la censura.

Los movimientos juveniles contemporáneos muestran una posición política frente a algunos de los grandes desafíos que enfrenta la región latinoamericana; pretenden atender a estos conflictos más allá de las soluciones que les brinda el sistema, poniendo en juego trasmutaciones habituales y adoptando prácticas con sentidos políticos antagonistas. Las asambleas, los consensos, sentires comunes, canciones, bailes, carteles, proyecciones, manifestaciones y demás actos colectivos, más allá de sus

23 Nótese que tanto Brasil como México realizaron elecciones nacionales en 2018. Brasil registró 78,72\% de participación ciudadana y México de 63,42\%. A pesar de ser altas, ambas cifras no batieron un record frente a otros años. En la nación brasileña, donde el voto es obligatorio, se fortaleció el abstencionismo (21,28\%), mientras que en México la elección se orientó más al voto de castigo a los partidos antecesores, dando $53,91 \%$ al vencedor. Las movilizaciones juveniles analizadas no representan una contraoposición electoral, sino más bien una alternativa de participación política. 
contradicciones, son ya una muestra clave de desafiar el individualismo y construir contracultura política.

\section{Referencias}

Acayaba, C. (2016). Estudantes vão aos EUA denunciar suposto abuso da PM em ocupações". G1 São Paulo, 1 de abril. Recuperado de http://g1.globo.com/sao-paulo/noticia/2016/04/ estudantes-vao-aos-eua-denunciar-suposto-abuso-da-pmem-ocupacoes.html

Andrade, H. (2018). Prácticas políticas juveniles contemporáneas. Los casos de \#YoSoy132 y \#TodosSomosPolitecnico en Ciudad de México y Movimiento Passe Livre y de los Secundaristas en Ciudad de São Paulo-Brasil. Tesis de Maestría, Ciudad de México: UNAM.

Araújo, P. (2016). Manifestantes se dizem perseguidos pela polícia de SP. Vice, 18 de octubre. Recuperado de https://www.vice. com/pt_br/article/vv485j/manifestantes-se-dizem-perseguidos-pela-policia-de-sp

Arditi, B. (2015). Las insurgencias no tienen un plan -ellas son el plan: performativos políticos y mediadores evanescentes. En $\mathrm{Sa}$ lazar y Cabrera (coordinadores). Nos quieren enterrar, olvidan que somos semilla; el devenir de las nuevas insurgencias (pp. 5784). México D.F.: UAM-X.

Borba, M., Felizi, N. y Reys J. (Orgs.). (2014). Brasil em movimiento, reflexões a partir dos protestos de junho. Río de Janeiro: Rocco.

Cadenatres Noticias. (2014). Youtube, 3 de octubre. Recuperado el 17 de diciembre de 2018 de https://www.youtube.com/ watch?v=JIOq-_WFziQ

Campos, A., Medeiros, J. y Ribeiro, M. (2016). Escolas de luta. São Paulo: Veneta.

Castells, M. (2012). Redes de indignación y esperanza. Madrid: Alianza.

Celorio, M. (2016). La desmovilización social: un enfoque para estudiar la dualidad del movimiento social contemporáneo. En L. Jiménez (Coord.), Jóvenes en el mundo globalizado (pp. 43-72). México D.F.: UNAM.

Del Águila, R. (2002). La participación política como generadora de educación cívica y gobernabilidad. Revista Iberoamericana de Educación, (12). Educación y gobernabilidad democrática 
Dupuis-Déri, F. (2014). Black Blocs. São Paulo: Veneta.

Easton, D. (1969). Enfoques sobre teoría política. Buenos Aires: Amorrortu.

Foracchi, M. (1972). A juventude na sociedade moderna. São Paulo: Ed. de São Paulo.

García, I. (2013). Las 11 frases que marcaron el "viernes negro" de Peña Nieto. ADN Político, 11 de mayo. Recuperado de http:// www.adnpolitico.com/gobierno/2013/05/09/las-11-frases-que-marcaron-el-viernes-11-de-pena-nieto

Hernández, L. (2014). Vándalos queman puerta de Palacio Nacional. Excelsior, 9 de noviembre. Recuperado de http:/ / www.excelsior. com.mx/comunidad/2014/11/09/991346

Huntington, S. (1972). El orden político de las sociedades en cambio. Buenos Aires: Paidós.

INEGI. (2013). Panorámica de la Población Joven en México desde la perspectiva de su condición de actividad 3013. Recuperado de http:/ / www.inegi.org.mx/prod_serv/contenidos/espanol/bvinegi/productos/estudios/sociodemografico/panora_joven/DoctoJovenes.pdf

Martins, C, y Cordeiro, L. (2014). Revolta popular: o limite da tática. Passa Palabra, 27 de mayo. Recuperado de http:/ / passapalavra.info/2014/05/95701

Melín, A. (2012). Uso de redes en la elección fue inédito: proliferaron trolls, bots y hasta mensajes de odio. MVSnoticias, 5 de julio. Recuperado de http:/ / www.noticiasmvs.com/\#!/noticias / uso-de-redes-en-la-eleccion-fue-inedito-proliferarontrolls-bots-y-hasta-mensajes-de-odio-241

Micha A. (2014). Youtube, 13 de noviembre. Recuperado el 17 de diciembre de 2018 de https://www.youtube.com/ watch?v=wuBD3RLIIEE

Milena, L. (2016). Secundaristas são perseguidos e espancados por PMs em SP. RBA, 1 de noviembre. Recuperado de http:/ / www. redebrasilatual.com.br/educacao/2016/11/secundaristassao-perseguidos-e-espancados-por-pms-em-sp-5628.html

Miranda, F. (2014). Violentos prenden fuego a puertas de Palacio Nacional. Milenio, 9 de noviembre. Recuperado de http:/ /www.milenio.com/policia/Deja-detenidos-protestas-DF-normalistasPalacio-Nacional-anarquistas-marcha_0_406159391.html

Modonesi, M. (2016). El principio Antagonista. México D.F.: ITACA. 
Noticieros Televisa. (2014). Youtube; 29 de septiembre. Recuperado el 17 de diciembre de 2018 de https://www.youtube.com/ watch?v=HzfUOfNqSOM

OCDE. (2015). Panorama de la educación 2015 México. Recuperado de https://www.oecd-ilibrary.org/docserver/eag-2015-es.pd f?expires $=1523906545 \&$ id $=$ id\&accname $=$ guest\&checksum $=6$ A02BD7F3F6B12A668B03EE91C8431E2

OCDE/CEPAL/CAF. (2016). Perspectivas económicas de América Latina 2017: Juventud, competencias y emprendimiento. París: OECD Publishing. Recuperado de http://dx.doi.org/10.1787/ leo-2017-es

OIT. (2013). Panorama Laboral 2013 América Latina y el Caribe. Lima: OIT. Recuperado de http://www.ilo.org/wcmsp5/groups/ public/---americas/---ro-lima/documents/publication/ wcms_232760.pdf

Pineda, C. (2017). Ayotzinapa: indignación y antagonismo, movimiento estudiantil y política asamblearia. En M. Modonesi, Militancia, antagonismo y politización juvenil en México (pp. 49102). México D.F.: ITACA.

Rancière, J. (1995). La mésentente. París: Galilée.

Red Política. (2014). ENTÉRATE: Así se pronunció el Colmex por Ayotzinapa. Recuperado de http://www.redpolitica.mx/nacion/enterate-asi-se-pronuncio-el-colmex-por-ayotzinapa

Reguillo, R. (2013). Culturas juveniles formas politicas del desencanto. Buenos Aires: Siglo XXI.

Reguillo, R. (2010). La condición juvenil en el México contemporáneo. Biografías, incertidumbres y lugares. En R. Reguillo (Coord.), Los jóvenes en México (pp. 395-429). México D.F.: Fondo de Cultura Económica.

Rosati, C. y Souza, F. (2014). Manifestante preso em ato em SP é transferido para presídio no interior. Folha de S. Paulo, 25 de junio. Recuperado de http://www1.folha.uol.com.br/ poder/2014/06/1476185-manifestante-preso-em-ato-emsp-e-transferido-para-presidio-no-interior.shtml

Rovira, G. (2017). Activismo en red y multitudes conectadas, comunicación y acción en la era de internet. México D.F.: UAM.

Salvadori, F. y Berna, M. (2016). Manifestantes suspeitam que PM usou agente infiltrado para fazer prisões em SP. Revista GGN, 8 
de septiembre. Recuperado de http://jornalggn.com.br/ noticia / manifestantes-suspeitam-que-pm-usou-agenteinfiltrado-para-fazer-prisoes-em-sp

Servín, M. (2012). Policías de un grupo llamado relámpago detuvieron a menores. La Jornada, 3 de diciembre. Recuperado de http:/ / www.jornada.unam.mx/2012/12/03/capital/035n1cap

Tarrow, S. (2004). El poder en movimiento. Los movimientos sociales, la acción colectiva y política. Madrid: Alianza.

Toret, J. (2013). Tecnopolítica: La potencia de las multitudes conectadas. Barcelona: UOC.

Valenzuela, M. (2015). Las voces de la calle... y de las redes sociales, los movimientos juveniles y el proyecto neoliberal. En M. Valenzuela (Coord.), El sistema es antinosotros, culturas, movimientos y resistencias juveniles (pp. 29-67). México D.F.: UAM.

Valenzuela, M. (2009). El futuro ya fue. Socioantropología de l@s jóvenes en la modernidad. México D.F.: COLEF.

Van Dijk, T. (1999). El análisis del discurso. Anthropos, (186), 23-36.

VV.AA. (2014). Brasil em Jogo, oque fica da copa e das olimpiadas? São Paulo: Boitempo.

Youtube. (2012). 14 de mayo. Recuperado el 17 de diciembre de 2018 de:https://www.youtube.com/watch?v=P7XbocXsFkI

Youtube. (2014). 1 de octubre. Recuperado el 17 de diciembre de 2018 de https:/ / www.youtube.com/watch?v=uEkYb-RJEeM 